\title{
A GIS-Based Decision-Support Tool for Integrated Water Resources Management in the Middle Olifants River System
}

\author{
Christian Jolk ${ }^{1}$, Harro Stolpe ${ }^{1}$, Roman Wössner ${ }^{2}$ and Andreas Abecker ${ }^{2}$ \\ ${ }^{1} \mathrm{eE}+\mathrm{E}$ Environmental Engineering and Ecology, University of Bochum \\ ${ }^{2}$ Disy Informationssysteme GmbH, Karlsruhe/Germany · andreas.abecker@disy.net
}

Short paper

\begin{abstract}
We describe qualitative planning and decision support for Integrated Water Resource Management. The underlying method assesses the contamination risk of water resources on a quaternary catchment level, in order to identify hot-spot areas with high problem intensity and with a priority call for action. The method has been fully automated with the help of the Disy Cadenza workbench. The results have been made available to decision makers through a WebGIS (Cadenza Web) and through a Tablet-GIS (Cadenza Mobile) for offline usage.
\end{abstract}

\section{Introduction}

The first step of Integrated Water Resources Management (IWRM) is to scan the overall area under consideration, to identify sub-areas with water quality problems, and rank these sub-areas according to the level of problem intensity in order to decide where to start with water management measures. To realize this first step of IWRM, the R\&D project "Integrated Water Resources Management in the Middle Olifants Area, South Africa" developed a methodological concept and implemented this concept as a GIS-based planning and decision support tool. The method and tool examine a river basin at the quaternary catchment level, in order to identify hot-spot areas with high problem intensity. The approach is based on results of the joint R\&D project "IWRM Vietnam" (cf. JOLK et al. 2010; ZINDLER et al. 2012), which were transferred to the situation and data availability in South Africa.

\section{Methodological Approach}

The underlying database consists of spatial geodata with topological and hydrographic base data, as well as references to entities relevant for water management like settlements, agricultural areas, industrial sites, etc.

The contamination risk describes the risk of water resources being polluted with impurities. It is established by a combination of qualitative approximations of (a) the resource sensitivity of water resources (surface water, groundwater), and (b) the contamination potential of various contaminant-related land uses (agriculture, settlements, industrial and commercial facilities). 
The resource sensitivity (1) of groundwater results from the aquifer depletion in combination with its significance for water supply, while the resource sensitivity (2) of surface water results from the local ecological status, the significance of surface waterbodies for water supply, and the hillside inclination (potential erosion).

The contamination potential (1) of diffuse contaminant sources originates from agricultural activities (fertilization, pesticides) and from wastewater discharge from settlements. The contamination potential (2) of point sources is based on commercial, industrial, and communal activities (industrial and commercial facilities, dumpsites, mining, etc.) with possible influx into groundwater or discharge into waterbodies.
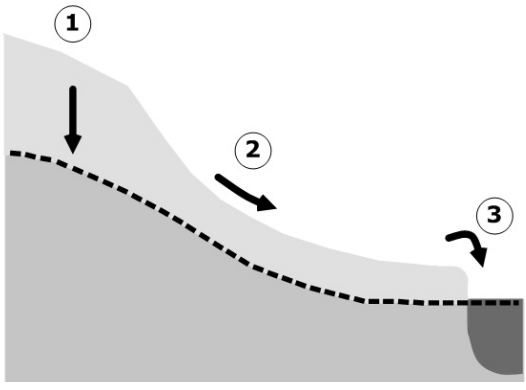

\section{Fig. 1:}

Contamination paths of pollutants affecting ground and surface water

We distinguish between three possible contamination paths (see Fig. 1):

Contamination path 1: infiltration of contaminants into groundwater

The agricultural contamination potential is based on the application of fertilizers and pesticides in agriculture. The contamination potential from settlements is based on the overall lack of wastewater treatment. Wastewater treatment facilities for settlements are regarded as direct discharge (path 3). The contamination potential from point sources is based on the possibility of contaminant infiltration close to industrial, commercial, and mining facilities.

Contamination path 2: erosive runoff and/or erosive discharge of contaminants into surface waterbodies

The agricultural contamination potential is based on erosive runoff and soil erosion. As there are generally no wastewater canals and no wastewater treatment plants in settlements, it is assumed that household wastewater mostly influences the water resources through path 1 (infiltration). Otherwise it would be regarded as direct discharge (path 3).

\section{Contamination path 3: direct discharge of contaminants into surface waterbodies}

The contamination potential from settlements is based on the direct discharge of wastewater. An interposed wastewater treatment plant would reduce the potential considerably. The contamination potential of point sources is based on the direct discharge of industrial, commercial, and mining wastewater.

The subsequent qualitative ranking process combines these partial assessments through decision tables, ranks all considered areas on a three-level scale, and thus helps to point out catchments with high problem intensity. Based on this information, decision makers in public administrations can recommend closer inspections and coordinate measures for river sub basins with priority need for IWRM measures. 


\section{GIS-Based Implementation of the Approach}

The methodological approach was realized using the Disy Cadenza Workbench ${ }^{1}$. Cadenza combines a spatial data warehouse system and a WebGIS. It can be used as follows:

- Spatial and factual data can be imported from existing sources (databases, GIS, files, geodata services) and stored in a harmonized spatial data warehouse.

- The process of filling the data warehouse may comprise operations for selecting the project-relevant data from different sources, checking or improving data quality, transforming wrt. syntactic and semantic consistency, and loading the data into one or more application-specific data schemata. The totality of these operations for filling a data warehouse is called ETL (extract - transform - load) processes.

- Then, Cadenza allows a repository of operation sequences to be built-up for querying, analyzing, and processing the data in the data warehouse, and for visualizing the analysis results as thematic maps, business diagrams, etc.

- The Cadenza functionalities and results can be accessed through a desktop tool (Cadenza Professional), a WebGIS (Cadenza Web), a Tablet-oriented mobile solution (Cadenza Mobile), and through OGC-compliant Web services.

The above (Section 2) introduced methods for assessing contamination risks in the IWRM South Africa project have been implemented as follows:

Geodata from the South African government, needed to assess the contamination paths 1, 2 and 3, were loaded into the data warehouse. As part of the ETL processes, data quality was checked, and necessary scale and representation changes were completed. The computation of contamination potential, resource sensitivity, and contamination risk was implemented as part of the ETL processes, as well as the ranking of river sub basins according to their priority for actions. Then the data warehouse contained all basic and derived parameters required for IWRM planning. These were visualized in thematic maps, and the maps were provided to end users in the public administrations.

\section{$4 \quad$ Results and Conclusions}

Fig. 2 shows a high-resolution thematic map about contamination risk from Path 1 (agriculture), combined with the positions of wells and 2-km buffers around them. The overall approach has been demonstrated to and validated with employees of the South African Department for Water and Sanitation (DWS) at the end of 2014, with a positive feedback. Further implementation steps at DWS are planned for mid 2015.

Altogether, the solution architecture allows that geodata are kept persistently in the data warehouse - and could later also be used for further purposes. The method for risk assessment and priority ranking is automated in GIS scripts during the ETL processes. The creation of thematic maps is realized through Cadenza analysis workflows. The presentation through the Cadenza WebGIS allows for wide dissemination and use of results within the

1 See http://www.disy.net/produkte/cadenza.html 
public administration without a need for dedicated software or hardware at the individual workplaces. The export to the Cadenza Mobile app facilitates on-site inspections, outdoors in places without an Internet connection.

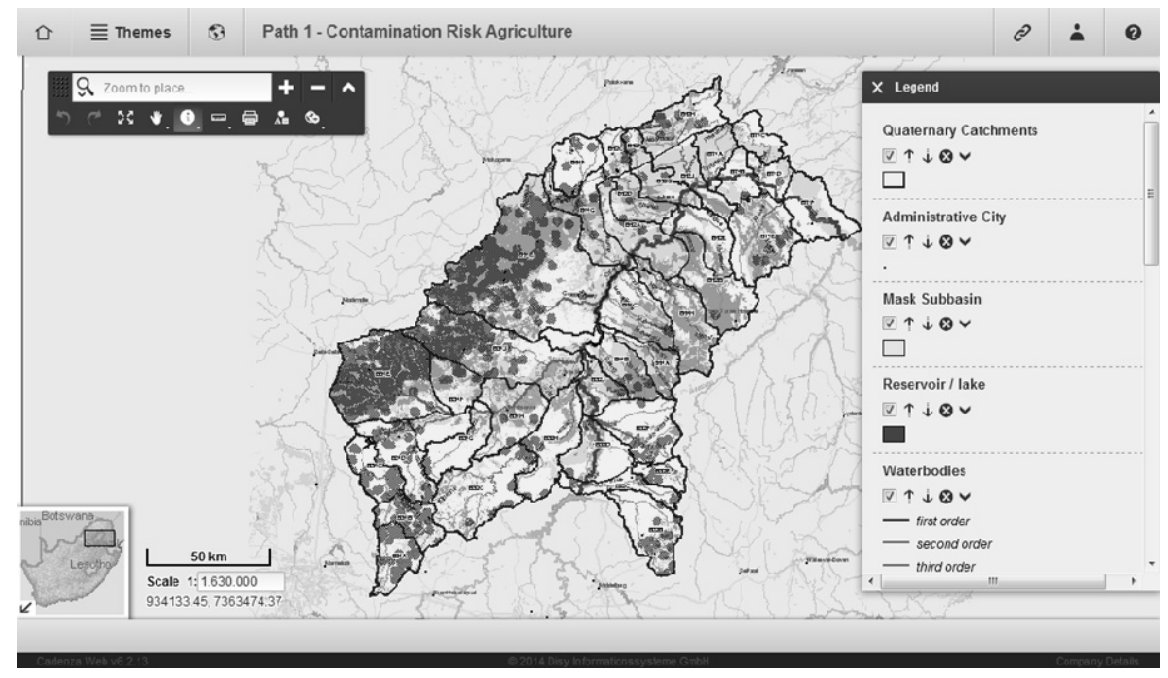

Fig. 2: Computed Thematic Map for Contamination Risk From Agriculture

In the remaining time until the project's end (December 2015), the documentation will be consolidated, and DWS employees will further test the solution. Additional help functions will be investigated, which could facilitate better understanding and usage of assessment results by the DWS employees. The qualitative approach is simple and robust against incomplete and erroneous data. Its transferability to other threshold countries will be examined in the future.

\section{References}

Jolk, C., Greassidis, S., Jaschinski, S., Stolpe, H., Zindler, B. (2010), Planning and Decision Support Tools for the Integrated Water Resources Management in Vietnam. Water 2010, 2 (4), 711-725.

Zindler, B., Borgmann, A., Greassidis, S., Jaschinski, S., Jolk, C., StolPe, H. (2012), Planning and Decision Support Tools for Integrated Water Resources Management (IWRM) on River Basin Level in the Southeast-Asian Region on the Example of Vietnam: Tools for Water Quantity and Quality Risk Assessment. In: LuO, Y. (Ed), Novel Approaches and their applications in risk assessment. InTech, Rijeka, 37-58. 